\title{
Infusing Cultural "genetic codes" into Contemporary Design Education with Chinese pattern as the Medium
}

\author{
Lisha LI \\ Yanan University, No. 580 Shengdi Road, Yanan, Shaanxi, China \\ IIs9010@126.com
}

Keywords: Chinese pattern, design education, traditional cultural, genetic code.

\begin{abstract}
This study analyzes the evolution of Chinese pattern's artistic style, and illustrates the cultural connotations contained in traditional pattern with examples, which under the background of the cultural development of contemporary design education in China. Then, it is concluded that colleges should use Chinese pattern as the medium to inject the cultural "genetic codes" into contemporary design education.
\end{abstract}

\section{Introduction}

Recently, many teaching methods of design in China are based on the western design education theory. But with the expansion of the differences between Chinese and western cultural connotation, the limitations of Chinese art education in the field of national culture have been highlighted. However Chinese pattern is an important part of traditional culture, which runs through the whole process of historical development and reflects the aesthetic style of different periods. Therefore, under the background of cultural globalization, the cultural identity of Chinese pattern in contemporary design education to maintain the particularity and independence of traditional culture is of great significance. So the contemporary design education should be based on the excellent traditional culture and aesthetic ideal of the nation, absorb advanced foreign design education ideas, then integrate the Chinese's thinking mode and use traditional Chinese pattern as the medium infusing cultural "genetic codes" into design education. After that, Chinese contemporary design can be developed with more national characteristics.

\section{The evolution of Chinese pattern in past dynasties}

Chinese pattern has been handed down over the centuries, forming a unique national artistic style. Its rich connotation reflects the different social and historical forms over thousands of years, also shows the needs of various strata for culture and art. The earliest pattern in China originated from totem worship. Those patterns were mainly appeared on painted pottery in primitive society. From the typical "fish pattern" and "dance pattern" with witchcraft meaning to the later geometric pattern such as triangle pattern, wave pattern, net pattern, it can be seen that the primitive society pattern has realized the transformation from the realistic totem meaning to the abstraction.

When the society developed to the Shang and Zhou Dynasties with bronze pattern as the main pattern, they usually take some animal image as the prototype, then with exaggerated deformation or artificial combination, finally form unrealistic artistic image, which makes the design content of this period seem mysterious and dignified. And on the basis of exaggerating and abstracting the shape of primitive society, the symbol of the ruling class's rights is added. Then in Spring and Autumn and Warring States Period, the arrangement of pattern has changed from "orderly" to "disorderly".

In Qin and Han Dynasties, there was a great amalgamation of Chinese culture. The artistic style centered on "ritual" is mainly embodied in the stone pattern of Han Dynasty. In the end of the Eastern Han Dynasty, Buddhism was introduced into China, which led to the rise of decorative patterns on Buddhist architecture. And people liked to use lotus as decorative pattern. Lotus flower is the symbol of Pure Land in Indian Buddhism, which reflecting the great influence of Buddhism on Chinese patterns at that time. In Tang Dynasty, Chinese pattern initially completed the 
transformation of nationalization, which forming a new pattern with plant pattern as the theme. For example, "Baoxiang flower pattern" has become a nationalized pattern. In Song Dynasty, most of the patterns used flower and bird, scenery, even poetry as the subject, and the lines were freely flowing, formed the artistic style close to nature. Among them, the "peony pattern" was the most common, which was strict in structure, and gave people a sense of harmony and grace.

Chinese traditional pattern has formed a pattern system with distinctive national characteristics in the Ming and Qing Dynasties. Auspicious pattern is the most representative, and that originated from people's auspicious ideas. Until in Qing Dynasty, it was developed to the degree that "the pattern must be intentional and the meaning is auspicious". It can be seen that Chinese traditional pattern is not only rich in resources, but also very deeply in meaning. They show their unique and charming national traditions and spirit of the times in a diverse and unified style. Those patterns evolve with the development of history, thus forming the unique artistic image of China.

\section{The cultural "genetic codes" of Chinese pattern}

\subsection{Nationality of Chinese pattern}

The so-called "genetic code" of culture is the carrier of recording the language, art, thought, culture and history on which a nation depends. Chinese traditional culture is the "root" of the nation. Therefore, contemporary art education should also look for the driving force from the context of the Chinese nation.

The nationality of Chinese pattern is manifested not only in the choice of pattern, but also in the decorative treatment of pattern. Like the representative of the totem of the Chinese nation - dragon and phoenix. Dragon is the mascot in people's mind. Under its blessing and protection, people will be healthy and safety. And it is composed of the most distinctive parts of many animals. Therefore, the dragon pattern became the symbol of the Supreme ruler's power, and only the Imperial Palace, the emperor's clothing can use the dragon pattern in ancient times.

Phoenix, which is considered a sacred bird, is the earliest bird among all birds. It has many characteristics of birds. The dragon and phoenix were endowed with mysterious power and were regarded as symbol of power and status. Ancient rulers called themselves dragons and phoenixes. The name of all the articles used by the empress carries the word "phoenix", such as "Phoenix Crown". The buildings and clothes in the palace were painted with gorgeous "phoenix pattern", which were delicately carved and reflected the wisdom of the Chinese nation. As the dragon and phoenix patterns were the representatives of the rulers, so in the carving and painting of the ancient palace architecture, and in the clothing, which were more colorful. And the style of each period's patterns has a new development on the original basis.

\subsection{Philosophy of Chinese pattern}

Chinese pattern is a way for people to grasp objective things and purify nature. And its form also reflects certain philosophical ideas. The theme and content of traditional patterns are closely related to traditional folk customs and people's lives.

Chinese traditional culture emphasizes the aesthetics of perfection, and the endless life of all creatures in the universe, and the harmony and unity between man and nature. The traditional philosophical ideas, such as "auspicious" concept, "circular reincarnation" concept and "harmony between man and nature", are embodied in the traditional patterns, which are the fusion of the phenomena of things in nature and the emotion of the subject. And it is also the highest realm of visual language symbols in the design and application of Chinese pattern.

The auspicious concept reflects people's desire for auspiciousness. The traditional auspicious pattern of the Qing Dynasty is the best embodiment of auspicious ideas in the form of visual language. For example, the "Fu Shou Lian Mian" pattern is consisted of bats and peaches. And the Chinese pronunciation of "bat" is the same as the Chinese pronunciation of "blessing", so it has the meaning of blessing and auspiciousness, while the peach has the meaning of longevity. So it means that "both happiness and longevity". That is the true reflection of the public's inner needs and the 
objective carrier of the spiritual world. Beside that, the concept of endless and cyclical reincarnation is a basic philosophical thought formed by the influence of ancient Chinese cosmology, which is also widely used in traditional patterns. For example, the "Pan Chang" is one of the "Eight Treasures" in Buddhism. And "Pan Chang" pattern conveys the idea of endless and embodies a positive emotional sustenance for the pursuit of a happy life.

\section{The application of Chinese pattern in design education}

In the course of design education, school should rectify the curriculum structure, teaching material's selection and teaching concept of Chinese pattern teaching. The content of curriculum should be full of Chinese traditional national characteristics, and develop the advantages of the school area. Beside that, it should integrate all aspects to build a more complete curriculum, and make students to improve their own quality and ability.

First of all, in the course system, teacher should combine the characteristics of traditional culture to reform the course hours, learning content and assessment methods. At the same time, we should pay attention to the traditional teaching and the exploration of innovation, so that make pattern teaching close to the practical needs of the course. And we should make use of the characteristics of traditional pattern's culture which can establish the characteristics of the professional teaching. The structure of the curriculum needs to firmly grasp the needs of students' training. Improving students' comprehensive quality and cultural development as the teaching orientation, then forming the unity of teaching objectives in all aspects.

Secondly, the concept of pattern teaching can not be separated from the excellent traditional Chinese culture, nor can we ignore the development trend of modern art. In teaching, we should pay attention to the combination of theory with examples, and explore the combination of traditional pattern and modern art. That requires both comprehensive research of the curriculum and the thematic discussion. In the process of research, we should refer to excellent information of traditional pattern and analyze it with other subjects. Only in this way can the teaching content be better understood by students, and make students get inspiration from traditional culture.

At the same time, in daily teaching, the combination of traditional pattern and modern practical elements enables students to examine traditional national pattern from the perspective of modern art, and make the elements of traditional and modern design more in line with the aesthetic of modern life. Of course that, traditional pattern can not be separated from the evaluation of modern aesthetics, and can not be separated from the guidance of students' contemporary art in teaching. So after that students can design pattern with modern aesthetics.

All in all, art design education is a comprehensive and interdisciplinary education which integrates design, art, commerce and education. It should give full play to its educational function while achieving academic achievements, economic benefits and social effects. Nowadays, the educational concept of "big design" advocated by many colleges, and it broadens students' horizons of examining artistic design. It also advocates that the thinking mode of "big design" should be used to jump out of the narrow scope of "small design" so as to guide students to think new ideas. This not only makes students interested in other disciplines, but also encourages students to develop a new understanding of culture and a desire to re-create design. So the value of traditional culture is indispensable in breaking through the bottleneck of art design. Only by continuously injecting the "genetic codes" of Chinese culture into the development of contemporary art and design education, can the works designed have a unique artistic style. And only by constantly excavating the cultural connotation of Chinese traditional patterns in the new meaning of pattern teaching, Chinese contemporary design education is likely to get the best development.

\section{References}

[1] Chuanlong Wang, Chinese Traditional Pattern and Modern Design, ChongQing University, 2009. 
[2] Jin jing, Traditional Regression in Design Education, Journal of Wuxi Nanyang College, 2006. 